coroner should be reportable directly by the doctor. Under the present law a doctor need not report any death to the coroner-he is legally entitled to write "Multiple stab wounds" on a death certificate and send if off to the registrar, who then has a statutory duty to refer the death to the coroner. The new recommendations will oblige the doctor to refrain from giving a certificate in such cases and report the death directly to the coroner. This will be another good reason for more legal instruction in medical schools, otherwise young doctors will never know the identity of these reportable conditions.

The last recommendation affects the coroner rather than the doctor. At present the coroner notifies the registrar of the cause of death only if there has been a necropsy or an inquest. In the so-called "Form A" cases the coroner currently requires the reporting doctor to issue a certificate, but in future the coroner will have to obtain the cause from the doctor-albeit unconfirmed by necropsy-and deliver it for registration.

When he recently put these proposals before the medical profession the Registrar General emphasised that the Brodrick Committee had sought to encourage a doctor not to give a certificate if he was in any doubt about the cause of death. This, together with some of the changes described above, seems to make it inevitable that the proportions of deaths reported to coroners will increase. Though this can only be an advantage from the point of view of accuracy of mortality statistics it may not be popular with the public or their doctors. It will increase the number of coroners' necropsies, which outside London are almost entirely performed by National Health Service consultants. The British Medical Association has yet to respond with its opinion on these changes, but some of them seem too sensible to be resisted.

Professor of Forensic Pathology,

Home Office Pathologist,

Welsh National School of Medicine,

Royal Infirmary,

Cardiff CF2 1SZ

\section{Urological complications of renal transplantation}

Major urological complications after renal transplantation must always be regarded with concern. At best a patient with an absent or failing urine output may present a diagnostic problem. At worst overwhelming infection in a urinary fistula may threaten such a risk of death that a functioning graft may have to be removed. Few other complications have such a depressing effect on the morale of a renal unit. Furthermore, while rejection is seen by all concerned as unpredictable and so acceptable, the occurrence of urological complications is usually thought to reflect unfavourably on the surgical skill of a particular transplant team.

Attention has recently been focused on these problems in a review from Guy's Hospital of 1000 renal transplants, ${ }^{1}$ which usefully sums up and confirms much previous information. The incidence of complications varies from one unit to another from around $5 \%$ to $20 \% \cdot^{2-7}$ Relevant factors include the criteria for selection of recipients and whether all patients are included irrespective of their graft function-clearly a primarily non-functioning kidney cannot develop a urological complication. The most common problems are obstructive uropathy and fistulas from the upper urinary tract, and vesicoureteric reflux may be a potential source of illness.
The ureter may be obstructed by a stenosis of the intramural portion and as a complication of surgical technique in the construction of the neocystostomy. There seem to be two schools of thought on how this should be done. ${ }^{8-10}$ Some antireflux mechanism is thought advisable by both schoolsbut surgeons who prefer to open the bladder and construct a nipple or tunnel probably do so with greater conviction that reflux matters than those who use one of the quicker, simpler, extravesical techniques. The more complex methods might be expected to give more problems in the hands of the occasional transplanter or non-urologist.

Obstruction due to distal ureteric fibrosis may sometimes be due to chronic ischaemia as a result of the vascular occlusive effects of rejection on what is the endarterial supply to the ureter derived from the main artery to the kidney graft. Blood clots within the lumen and haematomas in the ureteric wall or outside it in the pelvic cavity may all cause obstruction.

The ureter may also be occluded by the round ligament, the spermatic cord, or the inferior epigastric artery (if it is not divided during the preparation of the recipient). Occasionally, obstruction of the pelviureteric junction of the "idiopathic" type is seen-not too surprising a finding, as most urologists have found that the condition can be intermittent or suddenly progressive in the normal course of events. Its occurrence does not therefore indicate that the condition was missed at retrieval of the kidney.

The ureter may also be constricted by a cystic lymphangioma. Collections of lymph are commonly found, particularly if patients are routinely examined by pelvic ultrasonography. They rarely cause trouble, however, unless they become surrounded by a thick membrane and slowly get bigger-a process reminiscent of a subdural haematoma. Whether the lymph is derived from the graft or the recipient's lymphatics is open to question. Nevertheless, some recent evidence suggests that cystic lymphangiomas can be prevented by painstaking attention to technique during mobilisation of the iliac vessels. ${ }^{11}$

Published reports have paid relatively little attention to the problem of lower urinary tract obstruction, and yet most units have found that enlargement of the prostate may be a cause of morbidity which may become apparent only after transplantation has restored a sufficient flow of urine for the resistance to outflow to become apparent. ${ }^{12}$ Removal of the catheter may precipitate retention, prostatism, exacerbation of upper urinary tract obstruction, or disruption of the sutures in the bladder; surgery to the prostate may be needed urgently.

Obstruction may present either as early anuria or as a fall-off in established urine output. Obstruction which develops before any urine has been produced may be impossible to differentiate from tubular necrosis (due mainly to the effects of ischaemia during harvesting) or from primary vascular thrombosis. The other important cause of diminishing or absent urinary output occurring at any stage after transplantation is, of course, rejection of the graft.

The diagnosis of obstruction is seldom obvious. The output of urine may not necessarily be diminished, particularly in the chronic state. The usual investigations familiar to urologists may present special problems in the patient with a transplant. Restricted powers of tubular concentration may give poorquality urograms, and renal scanning after injection of radioactive tracers may be more reliable-at least it provides a useful supplementary investigation to test for adequate perfusion, excretory function, and obstruction. ${ }^{13}$ Retrograde ureterography can be attempted, though it is often unsuccessful owing to the site of the reimplanted ureter being inaccessible. A better approach is to perform antegrade pyelography after 
direct percutaneous puncture of the kidney. ${ }^{14}$ This method has the added advantage that pressure-flow studies can easily be performed to confirm obstruction when the results of other tests are equivocal. All such methods should be preceded by ultrasonic scanning.

A ureteric fistula is still a dreaded complication in the immunosuppressed patient, with an incidence of between 5\% and $12 \%$ of transplants. Fistula is only half as common as obstruction, but the mortality - which may be as high as 33\%-is double. Most fistulas are due to human error. The sole arterial supply of a transplant ureter is the descending branch of the main artery or of its lower polar branch. Damage to the vessels can easily be sustained during donor nephrectomy, particularly if the hilum is dissected too enthusiastically or if the ureter is "skinned." This is particularly likely if there is a multiple arterial supply, as the ureteric branch may arise quite proximally from the small lower polar vessel. Leakage can also occur from an ischaemic polar calix if the kidney is segmentally infarcted.

Rejection may be another cause of ureteric ischaemia and necrosis. A dead ureter can still act as a conduit of urine for some time after its blood supply has been occluded, so that perforation and extravasation may be delayed. In some circumstances a kidney may recover from a rejection episode to resume production of urine, which can then leak from the ureter a week or two after its destruction from ureteric artery thrombosis.

Clinical recognition of extravasation from a fistula is not usually too difficult, since the patient may complain of tender induration over the graft and have swelling of the external genitalia. A mass may be palpable on pelvic examination, though this may be due to a cystic lymphangioma. An intravenous urogram may confirm extravasation, and again ultrasound is often helpful.

The Guy's experience emphasises that definitive surgical treatment should be undertaken without delay. No rules for technique can be laid down, but the surgeon will usually need to reimplant the ureter where it is viable, using the existing host ureter, swing up a flap of bladder after hitching it to the psoas, or rarely and reluctantly use a loop of bowel to connect pelvis to bladder or to the skin as a conduit diversion. ${ }^{15}$ In all cases prolonged splintage will be required, conveniently with the modern internal self-retained stent. ${ }^{16}$ If at all possible the dosage of steroids should be reduced.

The importance of vesicoureteric reflux in patients who have had transplants is controversial. ${ }^{91017-19}$ Matthew and his colleagues argued persuasively that it might be a cause of late deterioration in function mimicking chronic rejection. ${ }^{19}$ More recently other authors have described groups of patients in whom reflux is quite common, owing perhaps to the use of an extravesical technique of implantation, but they have been unable to incriminate reflux as a cause of deteriorating function or of lesser problems such as urinary infection and hypertension. If this view proves correct, it will provide further evidence of the relative unimportance of reflux of adult onset.

Renal transplantation is now a standard and straightforward surgical procedure. Once the incidence of avoidable complications has been minimised the urologist will be able to devote his attention to other challenging problems such as reconstruction of congenitally or surgically damaged or diverted urinary tracts before transplantation.

M C BISHOP

Consultant Urological Surgeon,

University Hospital,

Nottingham NG7 2UH
${ }^{1}$ Mundy AR, Podesta ML, Bewick M, Rudge CJ, Ellis FG. The urological complications of 1000 renal transplants. Br $\mathcal{F}$ Urol $1981 ; 53: 397-402$.

${ }^{2}$ Bewick M, Collins REC, Saxton HM, Ellis FG, McColl I, Ogg CS. The surgery and problems of the ureter in human renal transplantation. $\mathrm{Br} \mathcal{F}$ Urol $1974 ; 46: 493-510$.

${ }^{3}$ Malek GH, Uehling DT, Daouk AA, Kisken WA. Urological complications of renal transplantation. F Urol 1973;109:173-6.

${ }^{4}$ Palmer JM, Chatteriee SN. Urologic complications in renal transplantation. Surg Clin North Am 1978;582:305-19.

5 Salvatierra O Jr, Olcott C, Amend WA, Cochrum KC, Feduska NJ. Urological complications of renal transplantation can be prevented or controlled. $\mathcal{f}$ Urol 1977;117:421-4.

6 Waltzer WC, Woods JE, Zincke H, et al. Urinary tract reconstruction in renal transplantation. Mayo Clinic experience and review of the literature. Urology 1980;16:233-41.

${ }^{7}$ Ehrlich RM, Smith RB. Surgical complications of renal transplantation. Urology 1977;10, suppl 1:43-56.

${ }^{8}$ Hooghe L, Kinnaert P, Schulman CC, et al. Ureterocystostomy in renal transplantation: comparison of endo and extravesical anastomoses. World $\mathcal{f}$ Surg 1977;1:231-5.

${ }^{9}$ Lucas BA, McRoberts JW, Curtis JJ, Luke RG. Controversy in renal transplantation: antireflux versus non-antireflux ureteroneocystostomy. 7 Urol 1979;121:156-8.

${ }^{10}$ Debruyne FMJ, Wijdeveld PGAB, Koene RAP, Chafik ML, Moonen WA, Renders GA. Uretero-neo-cystostomy in renal transplantation. Is an antireflux mechanism mandatory ? Br $\mathcal{F}$ Urol 1978;50:378-82.

11 Burleson RL, Marbarger PD. Prevention of lymphocele formation following renal allotransplantation. F Urol 1982;127:18-9.

12 Shenasky JH. Renal transplantation in patients with urologic abnormalities. f Urol 1976;115:490-3.

${ }^{13}$ Burke JR, Counahan R, Hilson AJ, et al. Serial quantitative imaging with $99 \mathrm{Tcm}-\mathrm{DTPA}$ in pediatric renal transplantation. Clin Nephrol 1979;12: 174-7.

${ }^{14}$ Goldstein I, Cho SI, Olsson CA. Nephrostomy drainage for renal transplant complications. $\mathcal{F}$ Urol $1981 ; \mathbf{1 2 6}: 159-63$.

15 Kimbler RW, Zinckie H, Woods JE, Leary FJ, Roses J, DeWeerd JH. Supravesical urinary diversion in renal transplantation. Eur Urol 1977 ; 3:193-6.

${ }^{16}$ Berger RE, Ansell JS, Tremann JA, Herz JH, Rattazzi LC, Marchioro TL. The use of the self-retained ureteral stents in the management of urologic complications in renal transplant recipients. $\mathcal{F}$ Urol 1980;124: 781-2.

${ }^{17}$ Bishop MC, Sherwood T, Evans DB, Calne RY. Vesicoureteric reflux after renal transplantation. Urol Radiol 1980;2:109-11.

18 Nghiem DD, Goldman MN, Mendez GD, Lee HM. The significance of vesicoureteric reflux and renal transplantation. Urology 1981;18:542-5.

19 Matthew TH, Kincaid-Smith P, Vikraman P. Risks of vesicoureteric reflux in the transplanted kidney. N Engl f Med 1977;297:414-7.

\section{Letting intrauterine devices lie}

The old Gräfenberg ring, introduced in about 1928, was made of coiled silver wire and was usually renewed at yearly intervals. If it was left longer the silver tended to corrode and the ring might become embedded and difficult to remove. ${ }^{1}$ Its use fell out of favour, and the method was little used until the late 1950s, when the development of biologically inert plastics made possible the production of intrauterine devices that were cheap, simple to insert, and did not have to be changed at regular intervals.

Many types of intrauterine device were produced and evaluated in the 1960s, ${ }^{2}$ but the only two of these which are likely to be seen now are the Lippes loop and the Saf-T-Coil, both of which are recommended as suitable to remain in the uterus indefinitely. ${ }^{3}$ Copper-bearing devices such as the copper 7 and copper $T$ were introduced in the early 1970s, and replacement was recommended after two to three years of use because of the deterioration of the copper wire. ${ }^{5}$ As these devices have become much more popular than the larger inert intrauterine devices, the younger generation of family planning doctors have little experience of the loops and coils and have come to question the advisability of leaving them in the uterus for years on end. 